\title{
Evaluation of Performance of Coffee Harvesters
}

\author{
Allan L. Phillips ${ }^{1}$ \\ INTRODUCTION
}

Harvesting is one of several steps in the production process of an agricultural commodity, namely the recovery or removal of a desired portion of the plant and consolidation into a form suitable for subsequent transportation, storage, or further processing. The overall profit obtained from the production of any crop depends on the economy of the harvest operation.

The evaluation of any system or equipment for harvesting a certain crop can be made by comparison with alternative systems. Where a crop is traditionally harvested without the aid of machines, a proposed harvesting device can be evaluated by comparing it to the system which uses only manual labor.

Several factors enter into the determination of economy or efficiency of a harvesting system. The mathematical relationships among the various factors are developed here with special reference to coffee as the crop to be harvested.

\section{ANALYSIS}

The following symbols are used to denote the individual factors and parameters used in the analysis:
$A=$ Annual equipment costs, $\$ /$ year
$B=$ Operating costs for harvesting machine, $\$ /$ hour
$C=$ Overhead cost, $\$$ /unit
$D=$ Operating cost, $\$ /$ unit
$E=$ Machine performance, unit/hour
$H=$ Machine use, hours/year
$J=$ Annual output, units/year
$N=$ Number of men required, man-hours/hour
$P=$ Labor productivity, unit/man-hour
$Q=$ Quality effect, \$/unit
$R$ = Proportion of ripe fruit expressed as a decimal fraction
$S$. = Proportion of fruit lost or damaged during harvest, decimal fraction
$T=$ Extra cost of additional operations, \$/unit
$U=$ Unit cost for harvest operation, \$/unit
$V=$ Value of crop, \$/unit

1 Associate Agricultural Engineer, Agricultural Experiment Station, Mayagüez Campus, University of Puerto Rico, Mayagüez, P.R. 
$W=$ Wage rate, $\$$ hour

$Y=$ Change in yield, proportion expressed as a decimal fraction

The unit cost for the harvest operation, $U$, provides a performance standard which can be used to compare various harvest systems. The smaller the unit cost, the better the system. Thus it is desirable to develop an expression which relates $U$ to the various influential factors. These factors should include effects on yield and quality and additional costs arising from extra field preparation or processing operations required by the harvest system.

A convenient unit for harvested coffee would be hundred-weights (cwt.) of coffee berries. It often is desirable to express costs in terms of $\$ /$ acre, and this can be achieved by multiplying costs, expressed in terms of $\$ /$ unit, by yield expressed as units/acre.

Relationships among the various parameters can be established as follows:

Annual output: $J=E H$, cwt./year

Overhead costs: $C=A / J, \$ /$ cwt.

Operating costs: $D=B / E+N W / E$

Therefore $D=(B+N W) / E, \quad \$ /$ cwt.

The quality effect $Q$ takes into account additional costs and changes in yield or value of the crop:

$$
Q=T-V Y, \quad \$ / \text { cwt. }
$$

The change in yield, $Y$, is positive if yield increases and negative if it decreases.

The unit cost is now obtained as follows:

$$
U=C+D+Q, \quad \$ / \text { cwt. }
$$

When hand harvest is used as an alternative system, the above expressions still apply although several of the parameters are negligible. Thus $C=O, T=O$ and $D=W / P$. The parameter $Y$ may have a non-zero value, for example in the case where part of the production is lost due to a scarcity of labor. Therefore, the unit cost for hand picking can be expressed as follows:

$$
U=D-V Y, \quad \$ / \text { cwt. }
$$

To analyze the quality effect in more detail, additional parameters can be considered. Both ripe and green fruits normally are present on the coffee tree during harvest, and the ripe fruits have a higher unit value. Therefore, the proportion of ripe and green harvested by any system will influence the quality effect. For example, if ripe fruit has a value of $10 \$ / \mathrm{cwt}$. and 
green fruit a value of $8 \$ / c w t$., and the percent ripe $R=0.60$ when a machine harvester is used, then the value of the crop will be:

$$
V=0.60(10)+0.40(8)=9.20 \$ / c w t .
$$

This expression may be presented in a general form as follows:

$$
V=R(V 1)+(1-R)(V 2)
$$

where $V 1$ is the value of ripe fruit, $\$ /$ cwt. and $V 2$ is the value of green fruit, $\$ /$ cwt.

The above expression can be written as follows:

$$
V=V 1-(1-R)(V 1-V 2)
$$

The second term $(1-R)(V 1-V 2)$ should be added to $Q$ to evaluate the quality effect when determining unit costs. In the example, this would amount to $0.80 \$ / \mathrm{cwt}$. being added to the unit cost.

A distinction should be made between losses occuring during harvest and change in yield due to cultural modifications required by the harvest system. The quantity lost during harvest, $S$, represents fruit that the harvester misses, loses or damages. The yield change $Y$ includes this, and also must include reductions in yield due to pruning, tree spacing, or other conditions needed to accommodate the harvest equipment. For example, if the yield is reduced by 10 percent due to required cultural practices, and in addition 5 percent of the crop is lost or damaged during harvest, the contribution to the quality effect $Q$ will be as follows:

or

$$
\begin{aligned}
V Y & =V[-0.10-(0.90)(0.05)] \\
Y & =-0.10-0.045=-0.145
\end{aligned}
$$

If $V 1=10 \$ /$ cwt., then $1.45 \$ /$ cwt. should be added to the unit cost.

\section{EXAMPLES}

An example can be developed, comparing hand picking with a portable picking aid. The performance data for the portable picking aid is based on actual field trials.

Hand harvest:

$$
\begin{aligned}
& D=4.00 \$ / \text { cwt. } \\
& Y=0 \\
& U=4.00 \$ / \text { cwt. }
\end{aligned}
$$


Machine harvest:

Total equipment costs $\$ 720$. Depreciated over 4 years, plus 20 percent for interest and overhead.

$$
\begin{aligned}
& A=216.00 \$ / \mathrm{yr} . \\
& B=0.25 \$ / \mathrm{hr} . \text {, operating costs } \\
& N=3 \mathrm{men} \\
& W=1.00 \$ / \mathrm{hr} . \\
& E=180 \mathrm{lb} . / \mathrm{hr} .=1.80 \mathrm{cwt} . / \mathrm{hr} . \\
& \text { Unit operating costs: } \\
& D=(B+N W) / E=(.25+3.00) / 1.8 \\
& D=1.805 \$ / \text { cwt. }
\end{aligned}
$$

Assume the machine operates $1000 \mathrm{hr}$. per year, then

$$
\begin{aligned}
& J=E H=(1.80)(1000)=1,800 \mathrm{cwt} . / \mathrm{yr} . \\
& C=A / J=216.00 / 1,800=0.12 \$ / \mathrm{cwt} .
\end{aligned}
$$

Assuming that the yield is reduced by 5 percent due to the requirement of the machine, and 5 percent of the crop is lost or damaged during harvest, and also that the harvested fruit is 80 -percent ripe with $V 1=10$ $\$ /$ cwt. and $V 2=8 \$ /$ cwt., then

$$
\begin{aligned}
& \qquad \begin{aligned}
& V=V 1-(1-R)(V 1-V 2) \\
& V=10-(.20)(2)=9.60 \$ / \text { cwt. } \\
& \text { Assume } T=0.20 \$ / \text { cwt. } \\
& Q=T-V Y+(1-R)(V 1-V 2) \\
& Q=.20-(9.60)(-.05-.0475)+(.20)(2) \\
& Q=.20+.935+.40=1.535 \$ / \text { cwt. }
\end{aligned}
\end{aligned}
$$

The unit cost for machine harvest is:

$$
\begin{aligned}
& U=C+D+Q=.12+1.805+1.535 \\
& U=3.54 \$ / \text { cwt. }
\end{aligned}
$$

Therefore, for this example, the machine has an advantage of 0.46 $\$ /$ cwt. over hand harvest.

\section{GRAPHICAL REPRESENTATION}

The analysis of performance standards allows a study of the effect of individual factors on the total unit cost. For example, if the yield reduction in the above calculations had been 10 percent rather than 5 , the total unit cost for machine harvest would be $3.98 \$ / c w t$., making the advantage only 2 cents per cwt. over hand harvest.

Also, if the machine were used only 200 hours per year, the overhead costs would be $0.60 \$ /$ cwt., thus making the total unit cost $4.02 \$ / \mathrm{cwt}$.

A graphical presentation is useful in indicating the effect of various individual factors on the total unit cost for harvesting. Usually one or two factors can be studied on a single graph, therefore several graphs are needed to represent all possible factors involved. 
In figure 1 , it is assumed that the quality effect $Q$ is constant, and the effect of varying the machine performance $E$ is studied.

Assumptions are as follows:

$$
\begin{aligned}
& Q=2.00 \$ / \text { cwt. } \\
& N=3 \text { men } \\
& W=1.00 \$ / \mathrm{hr} . \\
& B=0.25 \$ / \mathrm{hr} . \\
& A=216 \$ / \mathrm{yr} . \\
& H=1,000 \mathrm{hr} . / \mathrm{yr} .
\end{aligned}
$$

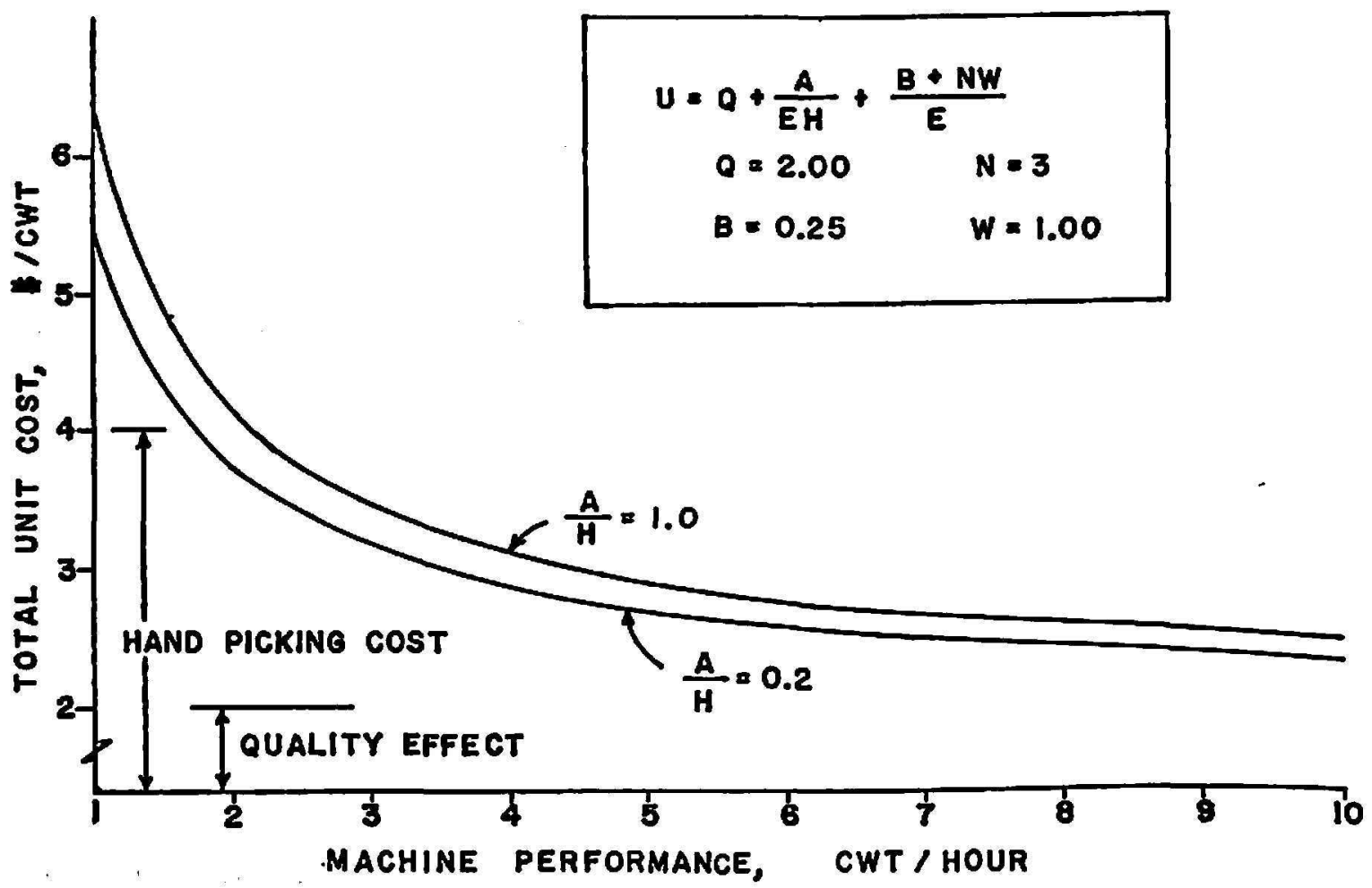

Fir. 1. -Relationships between total unit cost for harvesting and machine performance.

Figure 1 shows the relationship between the total unit cost for harvesting $(U, \$ /$ cwt.) and machine performance $(E, \quad$ cwt./hr). It can readily be seen that the effect of machine performance is very pronounced when the machine is in the range of one to four cwt./hr. When a machine's performance exceeds four cwt./hr., most of the total unit cost is due to the quality effect.

In figure 2; the relationship between overhead costs ( $C, \$ /$ cwt.) and annual output $(J, \quad c w t . / y x$.) is shown for various levels of annual equipment costs $(A, \$ / \mathrm{yr}$.). This graph illustrates the fact that expensive machines are justified if they are operated enough to develop a large annual output. For example, a $\$ 20,000$ machine $(A=4,000 \$ / \mathrm{yr}$. $)$ 


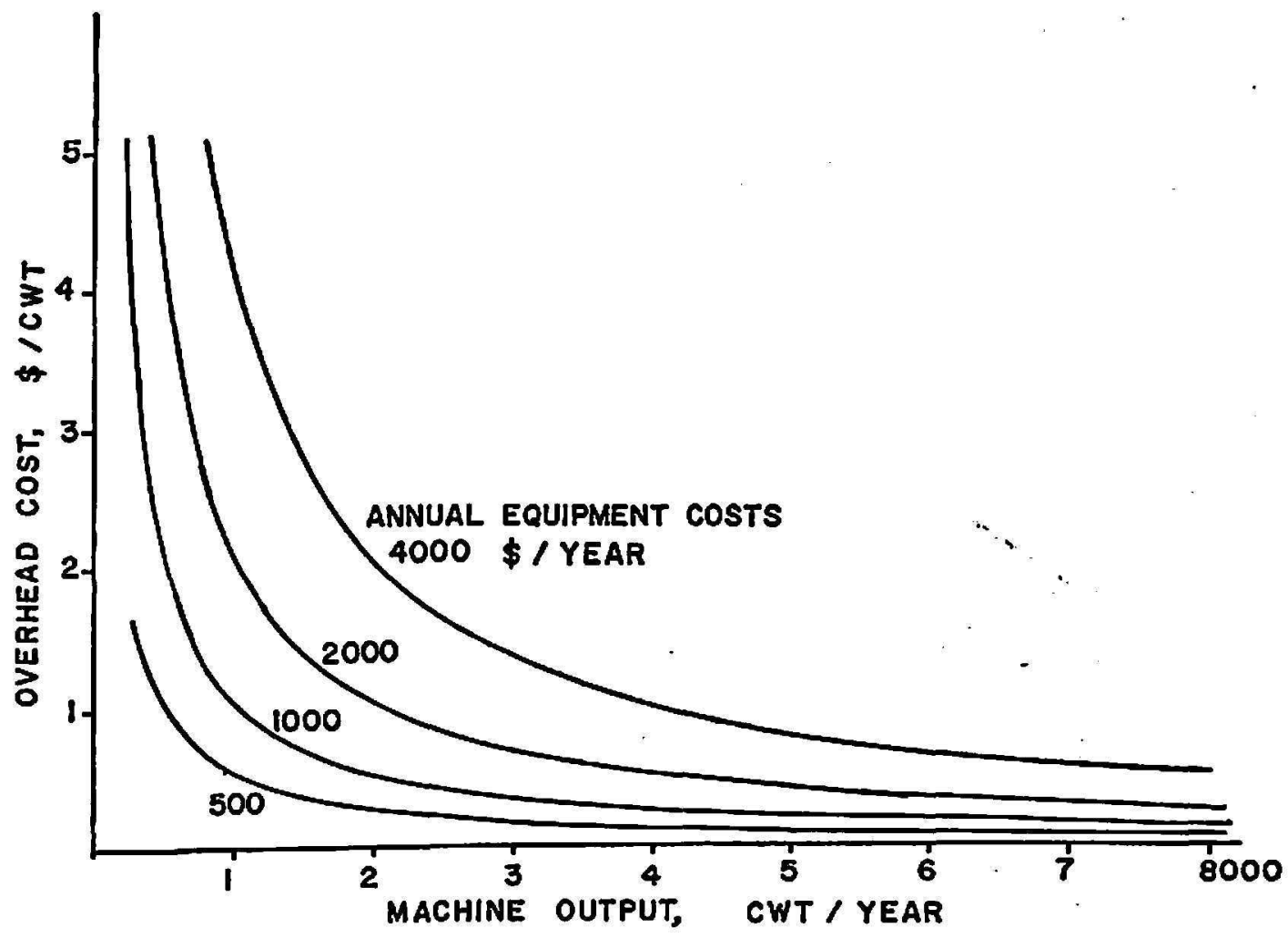

FrG. 2.-Relationships between overhead costs and annual output for various levels of annual equipment costs.

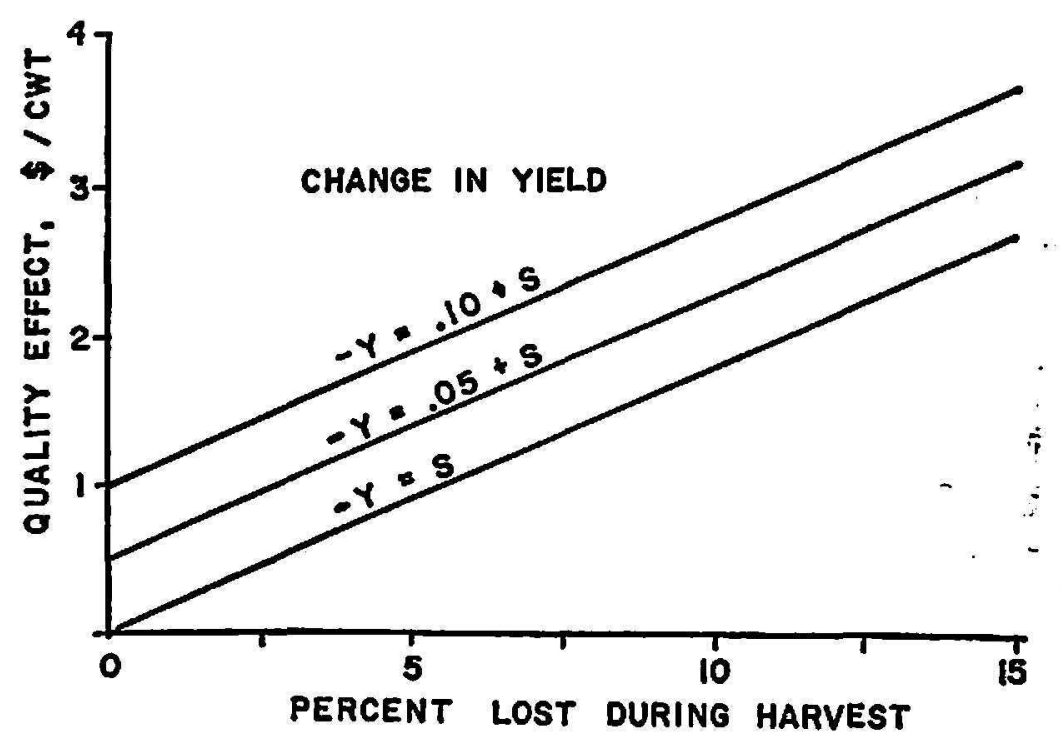

Fra. 3.-Contribution to the quality effect portion of the total unit cost due to losses in yield.

harvesting $8,000 \mathrm{cwt} . / \mathrm{yr}$. will result in lower overhead costs than a $\$ 5,000$ machine $(A=1,000 \$ / \mathrm{yr}$.) harvesting less than $2,000 \mathrm{cwt} . / \mathrm{yr}$.

The quality effect $(Q, \$ /$ cwt.) can be a predominant factor in the total unit cost. Figures 3 and 4 illustrate the contributions to quality effect 
that can be due to losses in yield and presence of green fruit in the harvested product. In figure 3 , it can be seen that the quality effect becomes prohibitive when the losses during harvest exceed 10 or 15 percent. From figure 4, one may conclude that ripeness percentages as low as 50 percent may be tolerated, but $\mathbf{7 0}$ to 80 percent seems like a reasonable minimum standard to be aimed for.

Another point worth noting, based on these two figures, is that it is more important to reduce losses by 5 percent than to increase the percent ripe fruit by 40 percent (assuming $V 1-V 2$ is $\$ 2.00$ ). A difference of 5 percent in the percentage lost will contribute approximately $0.90 \$ / \mathrm{cwt}$.

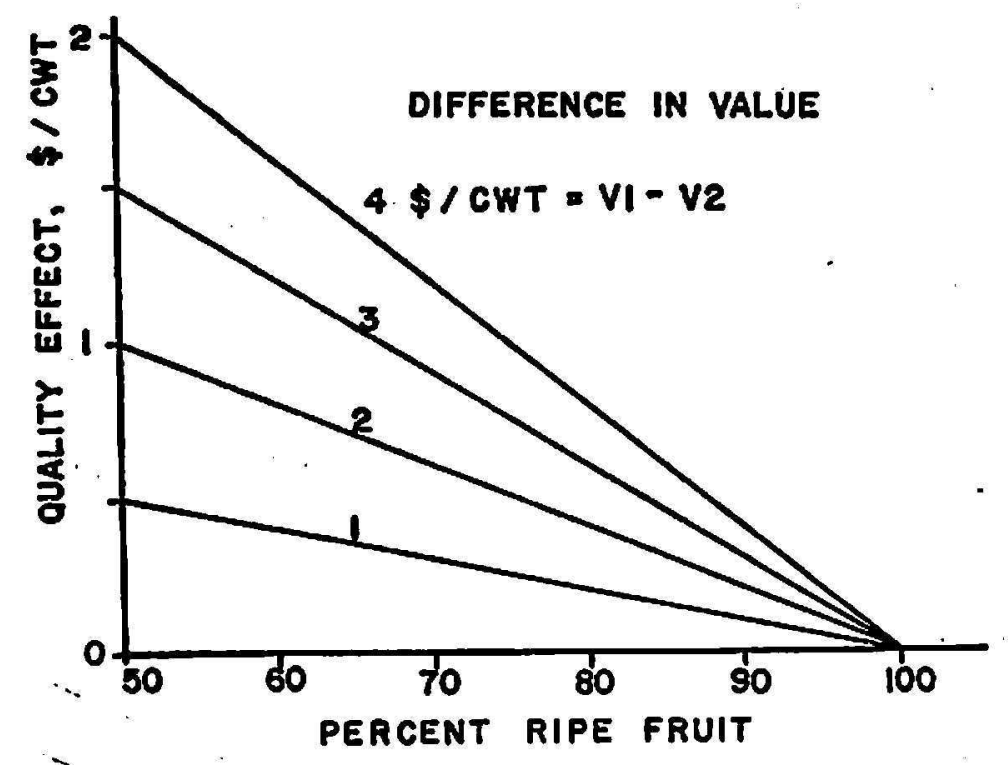

FiG. 4.-Contribution to the quality effect due to presence of green fruit in the harvested coffee at various price levels.

to the quality effect, whereas a difference of 40 percent in the percentage ripe will contribute only $0.80 \$ / \mathrm{cwt}$.

\section{CONCLUSIONS}

The values used in these analyses will depend on prevailing prices and wage rates. However, the mathematical relationships are always valid if all important factors have been taken into account, and can be used effectively when the appropriate values are inserted in the equations.

The mathematical relationships for expressing total unit costs provide a context for evaluating experimental machines. Field test data can be inserted into the equations to determine the relative economic advantage of various harvesting systems.

Furthermore, the analytical study of performance standards can provide indications of which factors are relatively important in determining total 
unit costs. Research and development effort then can be directed towards these individual factors, and the potential improvement in total unit costs can be appraised.

\section{SUMMARY}

An analysis is developed of the mathematical relationships among factors which determine the performance of harvest systems, with special reference to coffee. The analysis provides a context for evaluating harvest systems and indicates potential benefits resulting from improvements in any of the individual factors.

\section{RESUMEN}

Se analizó la relación matemática entre los factores que determinan el funcionamiento de sistemas de recolección, con referencia especial al café. El análisis provee un medio para evaluar sistemas de recolección e indica los beneficios potenciales que pueden derivarse de mejoras en cualquiera de los factores individuales. 